\title{
A New Design Procedure For Slot Arrays Fed By Single-Ridge
}

\section{Waveguide}

\author{
Yang Bing, XuHaitao, GaoZhiguo, Chen Zhen \\ Institute No.25 of the Second Academy China Aerospace Science \& Industry Corp. Beijing, 100854
}

Key words: decoupling, single-ridge waveguide, VSWR

\begin{abstract}
Design procedure for longitudinal slot arrays fed by air-filled rectangular waveguide including mutual coupling has been discussed and studied in many papers, and widely applied. Due tocomplexity of internal field, it is difficult toemploy the same method on slot arrays fed by ridge waveguide. In this paper, a newdesign procedureis introduced for slot arrays fed by single-ridge waveguide, which simplified the procedure of the previous one.A1 $\times 6$ array wasconstructed and tested, and the result validates the theory.
\end{abstract}

\section{Introduction}

Slot arrays fed by waveguide have been widely applied in radar and communication system,owing toa great number of merits, as high power capacity, low loss, simple feeding, easy manufacture, precise control of aperture distribution, and etc.Slots can be cut in the broad or narrow wall of the waveguide[2].In this paper, longitudinal slots cut in broad wall are discussed. In 1948, Stevenson founded the basis theory ofslotted waveguide in paper[1], and Oliner[2] has derived approximate expression of the admittance concerned to length and offset for the slot.Yee[3] has extendedOliner'svariational solution,proposed the slot resonant length, accounting for the offset of the slot from the center of the waveguide.The design procedure for slot arrays fed by rectangular waveguide has been deeply and numerously studied including mutual coupling,since 70 's by Elliott[6-8], which has been widely employedin waveguide slot array design fieldnowadays.Dolph-chebyscheff or Taylorpolynomials[9] are usually applied to synthesizecurrent distribution of slot array, for the sake of high gain and low side-lobe.

However, the bandwidth of slotted array fed by rectangular waveguide is an obvious defect[10]. An effective method to broaden the bandwidth is to separate anarray into several sub-arrays and feed them with a power divider[11]. Another option is to choose ridge waveguide instead of rectangular waveguide[12][13]. One design procedurefor slot arrays fed by single-ridge waveguide[14],deduced from ones by the rectangular waveguides, in which eigenvalue of ridge waveguide is required. A new procedure is presented in this paper, which avoids complex computation.

\section{New Design Procedure for slot arrays fed by rectangular waveguide}

In [6][8],Elliott has demonstrated the design procedure of slot array fed by rectangular waveguide, which includes self-admittance simulation of single waveguide slot[1][2], reciprocity theorem, and mutual coupling between two slots, which has been approximatedas two dipoles in space[7].

2.1 Traditional design procedure for slot array fed by rectangular waveguide

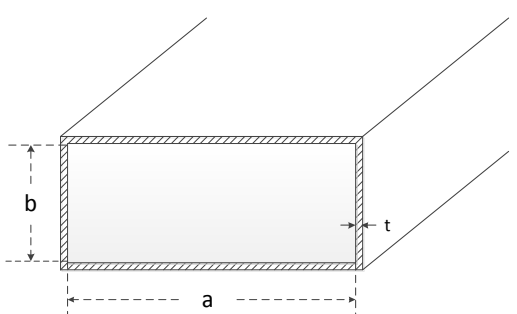




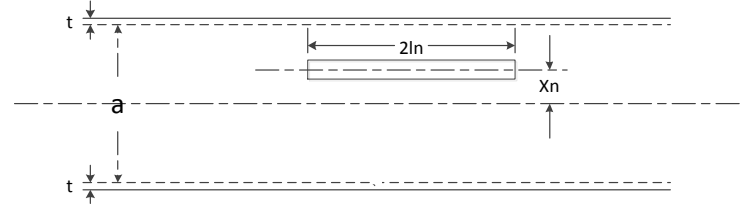

Figure 1. Rectangular waveguide (Up), longitudinal slot in the broad wall of a rectangular waveguide (Down)

Elliott deduced 2 equations (1) and (2) to calculate thelengthsand offsetsof each slotonce the desired radiation pattern and input admittance were determined.

$$
\begin{aligned}
\frac{Y_{n}^{a}}{G_{0}}=K_{1} f_{n} \operatorname{sinkl} l_{n} \frac{V_{n}^{s}}{V_{n}} \\
\frac{Y_{n}^{a}}{G_{0}}=\frac{K_{2} f_{n}^{2}}{Z_{n}^{a}}
\end{aligned}
$$

In which

$$
\begin{aligned}
& \mathrm{K}_{1}=-\mathrm{j}\left[\frac{8}{\pi^{2} \eta \mathrm{G}_{0}} \frac{(\mathrm{a} / \mathrm{b})}{(\beta / \mathrm{k})}\right]^{\frac{1}{2}} \\
& \mathrm{f}_{\mathrm{n}}=\frac{\cos \beta \mathrm{l}_{\mathrm{n}}-\operatorname{cosk} \mathrm{l}_{\mathrm{n}}}{\operatorname{sink} \mathrm{l}_{\mathrm{n}}} \sin \frac{\pi \mathrm{x}_{\mathrm{n}}}{\mathrm{a}} \\
& \mathrm{K}_{2}=\frac{292(\mathrm{a} / \mathrm{b})}{0.61 \pi(\beta / \mathrm{k})}
\end{aligned}
$$

Here, $G_{0}$ is characteristic admittance of the waveguide, $\eta$ is impedance of free space and $\eta=\sqrt{\frac{\mu_{0}}{\varepsilon_{0}}}=377 \Omega, \mathrm{k}$ and $\beta$ are free-space wave number and propagation constant respectively. $V_{\mathrm{n}}^{\mathrm{s}}$ is the mode voltage across the center of the slot, and $V_{n}$ is the equivalent voltage as figure 2 .

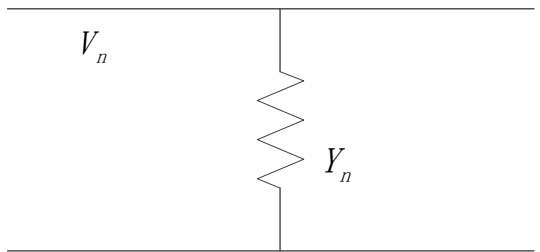

Figure 2. Definition of equivalent voltage

$\mathrm{Z}_{\mathrm{n}}^{\mathrm{a}}$ is active impedance of $\mathrm{nth}$ slot, and

$$
\mathrm{Z}_{\mathrm{n}}^{\mathrm{a}}=\mathrm{Z}_{\mathrm{nn}}+\mathrm{Z}_{\mathrm{n}}^{\mathrm{b}}
$$

In which

$$
\mathrm{Z}_{\mathrm{n}}^{\mathrm{b}}=\sum_{\mathrm{m}=1}^{\mathrm{N}} \frac{\prime \mathrm{V}_{\mathrm{m}}^{\mathrm{s}} \sin \mathrm{kl}_{\mathrm{m}}}{\mathrm{V}_{\mathrm{n}}^{\mathrm{s}} \sin \mathrm{kl}_{\mathrm{n}}} \mathrm{Z}_{\mathrm{mn}}
$$

$Z_{n n}$ is self- impedance of nth slot. $Z_{m n}$ is mutual impedance between the mth and nth slots, which is assimilated as half wavelength dipole and discussed in [7]. $\mathrm{V}_{\mathrm{m}}^{\mathrm{s}}$ andV $\mathrm{V}_{\mathrm{n}}^{\mathrm{s}}$ are mode voltages across shunt elements, respectively.

The design procedure could be summarized as: first of all, current distribution can be synthesized according to desired radiation pattern and side-lobe, thusinitialadmittances of each slot $Y_{n n}$ with its offsets and lengths of each slot are acquired. Afterwards, equation (1) and (2) should be employed to compute active admittance $Y_{n}^{a}$ of each slot. Once active admittance of the nth slot $Y_{n}^{\mathrm{a}}$ is achieved, $Y_{n n}$ should be adjusted to compensate the effect brought by mutual coupling, and offsets and lengths of each slot should be adjusted subsequently.Iterates the design procedure several times, final offsets and lengths of each slot of slot array are achieved.

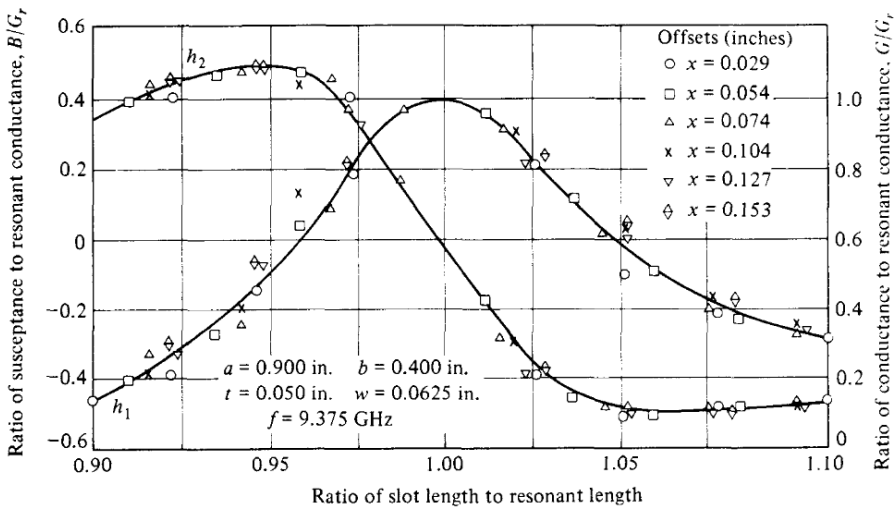

Figure 3.Normalized Self-Admittance Components for a Longitudinal Shunt Slot (by Stegen[4])

Usually after adjusted, self-admittances of slots won't be resonant anymore, due to effort of mutual coupling.

Instead,active admittances are purely real and accord with the desired current distribution.

\subsection{New method with assistance ofelectromagnetic calculating software}

There are 2 equations (1) and (2) proposed to design slot array fed by rectangular waveguide by Elliott. But usually only (2) is used, (1) barely employed in design procedure. In [6], formula (1) is defined at resonant point, and $Y_{n}^{a}$ is purely real For single slot, $Y_{n}^{\text {a is }} Y_{n n}$, which can be calculated by electromagnetic software, in this paper, HFSS is employed. And the computational model isas figure 4 .

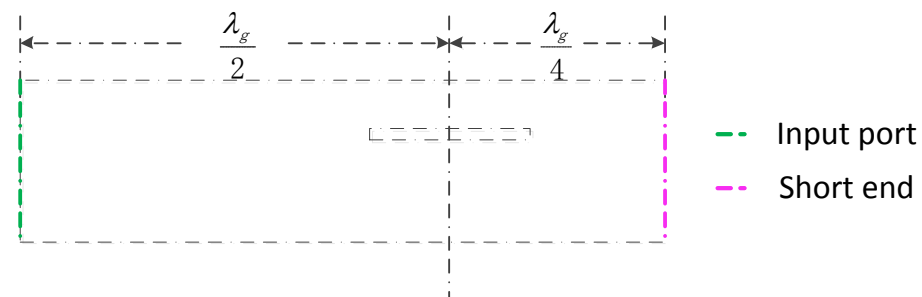

Figure 4. One-port model (short end) of slot fed by rectangular waveguide

As definition, $V_{n}^{s}$ and $V_{n}$, also can be computed through electromagnetic software. The model is shown in figure 5 .

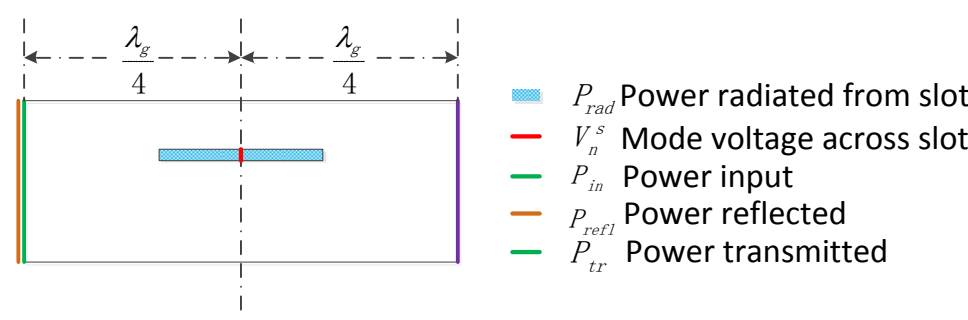

Figure 5. Two-port model (matched loaded) of slot fed by rectangular waveguide 
Slot can be considered as a lumped circuit as figure $2 . V_{n}^{S}$ can be read directly by HFSS. Relation of power radiated $\mathrm{P}_{\text {rad }}$ from slot gets from software and $\mathrm{Y}_{\mathrm{nn}}$ is calculated from the model of figure 4 . Therefore, equivalent voltage $V_{n}$ of nth slot is obtained

$$
\mathrm{V}_{\mathrm{n}}=\sqrt{\frac{2 \mathrm{P}_{\mathrm{rad}}}{\mathrm{Y}_{\mathrm{nn}}}}(9)
$$

Thus, $\mathrm{Y}_{\mathrm{nn}}, \mathrm{V}_{\mathrm{n}}^{\mathrm{s}}$ and $\mathrm{V}_{\mathrm{n}}$ are all computed through computational electromagnetic software directly or indirectly. Put all these values in (1), $\mathrm{K}_{1}$ isachieved.

For example, arectangular waveguide works at $\mathrm{f}_{0}=17.6 \mathrm{GHz}$, of whichwidth and height are $a=10.73 \mathrm{~mm}$ and $\mathrm{b}=$ $3.5 \mathrm{~mm}$ respectively. Calculated directly from(3), the result turnsK $\mathrm{K}_{1}^{\text {dir }}=1.6428$.

From formula (1) and electromagnetic software, $\mathrm{K}_{1}$ also can be calculated as aforementioned, written as $\mathrm{K}_{1}^{\mathrm{indir}}$, and the results are illustrated in table 1.

\begin{tabular}{|c|c|c|c|}
\hline No. & Slot length $(\mathrm{mm})$ & Slot Offset $(\mathrm{mm})$ & $\mathrm{K}_{1}^{\text {indir }}$ \\
\hline 1 & 8.3931 & 1 & 1.6783 \\
\hline 2 & 7.9 & 1 & 1.6524 \\
\hline 3 & 8.6 & 1 & 1.6184 \\
\hline 4 & 8.3931 & 1.3 & 1.6692 \\
\hline 5 & 8.3931 & 1.5 & 1.6455 \\
\hline
\end{tabular}

Table $1 . K_{1}^{\text {indir }}$ computed in aid of software for slot fed by rectangular waveguide

Relative error is defined as (10):

$$
\varepsilon_{\mathrm{K}_{1}}=\left\|\frac{\mathrm{K}_{1}^{\mathrm{dir}}-\mathrm{K}_{1}^{\mathrm{indir}}}{\mathrm{K}_{1}^{\mathrm{dir}}}\right\|
$$

And all results are less than $2 \%$.

\section{New Design Procedure for slot arrays fed by single-ridge waveguide}

Compared to rectangular waveguide, ridge waveguide has smaller size and wider bandwidth. In [14], Kim and Elliottapplied the same design procedure of last section on single-ridge waveguide, in which

$$
\mathrm{K}_{1}=\frac{2 \mathrm{k}_{\mathrm{T}}}{\mathrm{k}_{0}} \sqrt{\frac{\mathrm{k}_{\mathrm{T}}^{2}}{\omega \mu_{0} \beta_{10} \mathrm{G}_{0}}}
$$

$\mathrm{k}_{\mathrm{T}}$ isthe eigenvalue of the single-ridge waveguide for the dominant mode $\mathrm{TE}_{10}$. Computation of $\mathrm{k}_{\mathrm{T}}$ is described in [5], which is complicated and obscured.

The new method for calculate $\mathrm{K}_{1}$ discussed above will be appliedin later section to simplify the computation.

\subsection{New design procedure applied to computeK $K_{1}$ of slot}

\section{array fed by single-ridge waveguide}

As previous, $Y_{n n}, V_{n}^{s}$ and $V_{n}$ could be computed, and with equation(1), $\mathrm{K}_{1}$ could be calculated.

For example, a single-ridge waveguide, illustrated as figure 6,

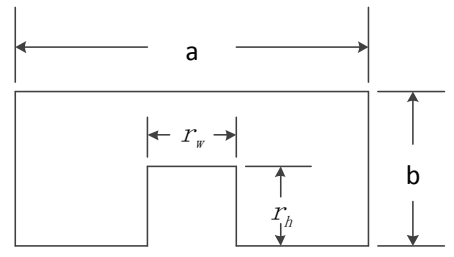

Figure 6.Geometry of single-ridge waveguide which works at $\mathrm{f}_{0}=17.6 \mathrm{GHz}$, and $\mathrm{a}=8.29 \mathrm{~mm}, \mathrm{~b}=$ $3.5 \mathrm{~mm}, \mathrm{r}_{\mathrm{w}}=3 \mathrm{~mm}, \mathrm{r}_{\mathrm{h}}=1.5 \mathrm{~mm}$.

\begin{tabular}{|c|c|c|c|}
\hline No. & Slot length $(\mathrm{mm})$ & Slot Offset $(\mathrm{mm})$ & $\mathrm{K}_{1}^{\text {indir }}$ \\
\hline 1 & 9.018 & 1.5 & 1.5263 \\
\hline 2 & 8.9 & 1.5 & 1.5200 \\
\hline 3 & 8.8 & 1.5 & 1.4868 \\
\hline 4 & 9.2 & 1.5 & 1.4737 \\
\hline 5 & 8.8251 & 1.2 & 1.5567 \\
\hline 6 & 9 & 1.2 & 1.5071 \\
\hline 7 & 8.7 & 1.2 & 1.5505 \\
\hline 8 & 8.6 & 1.2 & 1.5211 \\
\hline
\end{tabular}

Table $2 . \mathrm{K}_{1}^{\text {indir }}$ for slot fed by single-ridge waveguide above Relative error is defined as

$$
\varepsilon_{\mathrm{K}_{1}}=\left\|\frac{\operatorname{avr}\left(\mathrm{K}_{1}^{\mathrm{indir}}\right)-\mathrm{K}_{1}^{\mathrm{indir}}}{\operatorname{avr}\left(\mathrm{K}_{1}^{\mathrm{indir}}\right)}\right\|
$$

In which $\operatorname{avr}\left(\mathrm{K}_{1}^{\mathrm{indir}}\right)$ is average of $\mathrm{K}_{1}^{\text {indir }}$, and calculated as, $\mathrm{K}_{1}^{\text {indir }}=1.5178$

Error results are all less than $3 \%$.Therefore, $\mathrm{K}_{1}$ of single-ridge waveguide can be approximated as a constant through the method aforementioned,instead of complex formula (11)

\subsection{Example of slot array fed by single-ridge waveguide designed with new method}

One such case which can be instructive involves the design of a six-slot lineararray, shown as figure 7.

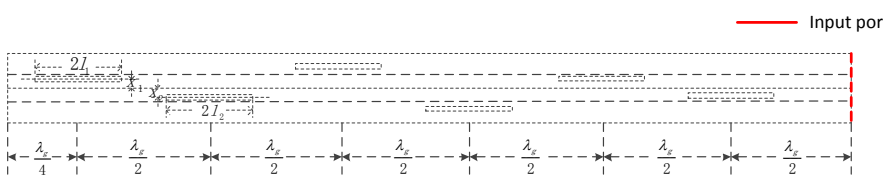

Figure 7.A $1 \times 6$ array of longitudinal shunt slots in the broad wall of a single-ridge waveguide

The slot current distribution accords Taylor synthesis and the side lobe is designed at $-25 \mathrm{~dB}$. Normalized current distribution is computed as:

$$
\begin{array}{llllll}
0.1010 & 0.1701 & 0.2289 & 0.2289 & 0.1701 & 0.1010
\end{array}
$$

Array works at $\mathrm{f}_{0}=17.6 \mathrm{GHz}$, and the waveguide wavelength is $\lambda_{\mathrm{g}}=22 \mathrm{~mm}$.Parameters of the ridge waveguide are

$$
\mathrm{a}=10 \mathrm{~mm}, \mathrm{~b}=3.5 \mathrm{~mm}, \mathrm{r}_{\mathrm{w}}=4 \mathrm{~mm}, \mathrm{r}_{\mathrm{h}}=1.7 \mathrm{~mm} \text {. }
$$

The slots' solution is:

$$
\begin{array}{ccc}
\mathrm{x}_{1}=0.5868 \mathrm{~mm} & 2 \mathrm{l}_{1}=8.2710 \mathrm{~mm} & \mathrm{~g}\left(\mathrm{x}_{1}\right)=0.0557 \\
\mathrm{x}_{2}=-0.9764 \mathrm{~mm} & 2 \mathrm{l}_{2}=8.4463 \mathrm{~mm} & \mathrm{~g}\left(\mathrm{x}_{2}\right)=0.1581 \\
\mathrm{x}_{3}=1.3436 \mathrm{~mm} & 2 \mathrm{l}_{3}=8.6033 \mathrm{~mm} & \mathrm{~g}\left(\mathrm{x}_{3}\right)=0.2862 \\
\mathrm{x}_{4}=-1.3436 \mathrm{~mm} & 2 \mathrm{l}_{4}=8.6033 \mathrm{~mm} & \mathrm{~g}\left(\mathrm{x}_{4}\right)=0.2862 \\
\mathrm{x}_{5}=0.9764 \mathrm{~mm} & 2 \mathrm{l}_{5}=8.4463 \mathrm{~mm} & \mathrm{~g}\left(\mathrm{x}_{5}\right)=0.1581
\end{array}
$$


$\mathrm{x}_{6}=-0.5868 \mathrm{~mm} \quad 2 \mathrm{l}_{6}=8.2710 \mathrm{~mm} \quad \mathrm{~g}\left(\mathrm{x}_{6}\right)=0.0557$

The radiation pattern is as figure 8 :

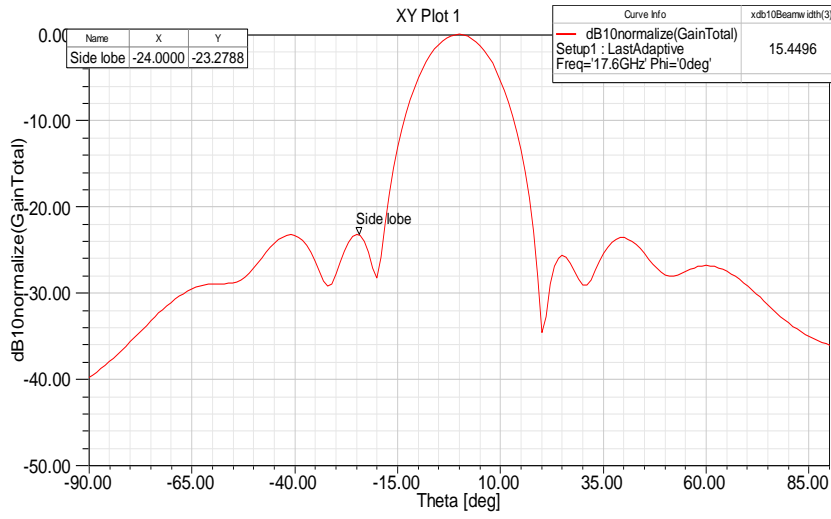

Figure 8.Pattern of the $1 \times 6$ slot array example

We get from the figure that the side lobe is at $-23.2788 \mathrm{~dB}$, nearly up to the request. At meanwhile, the desired normalized input admittance is equal to 1, butread from computational software, VSWR $=1.3866$.

With the method aforementioned, we get new solution:

$$
\begin{array}{ccc}
\mathrm{x}_{1}=0.7220 \mathrm{~mm} & 2 \mathrm{l}_{1}=8.2342 \mathrm{~mm} & \mathrm{~g}\left(\mathrm{x}_{1}\right)=0.0754+\mathrm{j} 0.0192 \\
\mathrm{x}_{2}=-1.1810 \mathrm{~mm} & 2 \mathrm{l}_{2}=8.4295 \mathrm{~mm} & \mathrm{~g}\left(\mathrm{x}_{2}\right)=0.2118+\mathrm{j} 0.0469 \\
\mathrm{x}_{3}=1.5530 \mathrm{~mm} & 2 \mathrm{l}_{3}=8.6098 \mathrm{~mm} & \mathrm{~g}\left(\mathrm{x}_{3}\right)=0.3554+\mathrm{j} 0.0622 \\
\mathrm{x}_{4}=-1.5530 \mathrm{~mm} & 2 \mathrm{l}_{4}=8.6098 \mathrm{~mm} & \mathrm{~g}\left(\mathrm{x}_{4}\right)=0.3554+\mathrm{j} 0.0622 \\
\mathrm{x}_{5}=1.1810 \mathrm{~mm} & 2 \mathrm{l}_{5}=8.4295 \mathrm{~mm} & \mathrm{~g}\left(\mathrm{x}_{5}\right)=0.2118+\mathrm{j} 0.0469 \\
\mathrm{x}_{6}=-0.7220 \mathrm{~mm} & 2 \mathrm{l}_{6}=8.2342 \mathrm{~mm} & \mathrm{~g}\left(\mathrm{x}_{6}\right)=0.0754+\mathrm{j} 0.0192
\end{array}
$$

The VSWR result reduces to 1.1499 , which approaches the expectation.Nevertheless, effect of thickness of waveguide, precision of the computation and other factors which impact the accuracy should be taken into account.

\section{Conclusion}

In this paper, a new design procedure for longitudinal broadwall slots fed by a single-ridge waveguide is presented, which is less complex in contrast to the traditional one. The new design procedure derives from slot array fed by rectangular waveguide, and extends to arrays fed by single-ridge waveguide. The new method simplifies the mathematic computation of $\mathrm{K}_{1}$ with the aid of electromagnetic computational software. Two examples are illustrated later. The first one proves $\mathrm{K}_{1}$ is nearly a constant also for shunt slots of single-ridge waveguide. The latter one, that is a $1 \times 6$ slot array, attains better VSWR after decoupling by the method. In conclusion, this new means assists us with in designing slot array fed by single-ridge waveguide.

\section{REFERENCES}

[1]. A. F. Stevenson, "Theory of slots in rectangular waveguides," J. Appl. Phys., vol. 19, pp. 24-38, Jan. 1948.

[2]. A. A. Oliner, "The impedance properties of narrow radiating slotsin the broad face of rectangular waveguide, Part I-Theory, Part II-Measurements,"IRE Trans. Antennas Propagat., vol. AP-5, pp. 4-20,Jan. 1957.

[3]. H. Y. Yee, "Impedance of a narrow longitudinal shunt silno ta slottedwaveguide array," IEEE Trans. Antennas Propagat, vol. AP-22, pp. 589-592, July 1974.

[4]. R. J. Stegen,"Longitudinal Shunt Slot Characteristics,"Hughes Technical Memorandum No. 261,Nov. 1951.

[5].J. P. Montgomery, "On the complete eigenvalue solution of ridge waveguide," IEEE Trans. Microwave Theory Tech., vol. MTT-19, pp. 547-555, June 1971.

[6].Robert S. Elliott ,L. A. Kurtz, “The Design of Small Slot Arrays,"IEEE Trans. Antennas Propagat, vol. AP-26, Mar. 1978.

[7].Robert S. Elliott, William R. O'Loughlin, “The Design of Slot Arrays Including Internal Mutual Coupling,"IEEE Trans. Antennas Propagat,vol. AP-34, No. 9, Sep. 1986.

[8].Robert S. Elliott, “An Improved Design Procedure for Small Arrays of Shunt Slots,"IEEE Trans. Antennas Propagat,vol. AP-31, No. 1, Jan. 1983.

[9].R. S. Elliott, "Design of Line-Source Antennas for Narrow Beamwidth and AsymmetricLow Sidelobes," IEEE Trans. Antennas Propagat, vol. AP-23, No. 1, pp. 100-107, Jan. 1975.

[10].MazenHamadallah"Frequency Limitations on Broad-Band Performance of Shunt Slot Arrays,"IEEE Trans. Antennas Propagat, vol. 31, No 7. Jul. 1989.

[11].J. C. Coetzee, J. Joubert, and W. L. Tan, "Frequency performance enhancementof resonant slotted waveguide arrays through the use ofwideband radiators or subarraying," Microwave Opt. Technol. Lett.,vol. 22, no. 1, pp. 35-39, Jul. 1999.

[12].J. R. Pyle. "The Cutoff Wavelength of the TE, Mode in RidgedRectangular Waveguide of Anv Aspect Ratio,'IEEE Trans. Microwave Theory Tech. vol.14, No. 4. Apr. 1966. [13].S. Hopfer, “The Design of Ridged Waveguides", IRE Trans. Antennas Propagat.vol. MTT-14, No. 4,Oct. 1955. [14]. David Y. Kim, Robert S. Elliott, A Design Procedure for Slot Arrays Fed by Single-Ridge Waveguide, IEEE Trans. Antennas Propagat, vol. 36, No. 11, Nov. 1988. 